\title{
Sustained inflammation I.5 years post-stroke is not associated with depression in elderly stroke survivors
}

\author{
Kate Noonan ${ }^{1,2}$ \\ Sheila G Crewther ${ }^{1,2}$ \\ Leeanne M Carey ${ }^{2,4}$ \\ Michaela C Pascoe 5 \\ Thomas Linden ${ }^{2,3}$ \\ 'School of Psychological Science, \\ La Trobe University, Bundoora, \\ Victoria, Australia; ${ }^{2}$ Florey Institute \\ of Neuroscience and Mental \\ Health, Melbourne Brain Centre, \\ Heidelberg, Victoria, Australia; \\ ${ }^{3}$ Institute of Neuroscience and \\ Physiology, University of Gothenburg, \\ Gothenburg, Sweden; ${ }^{4}$ Department of \\ Occupational Therapy, School of Allied \\ Health, La Trobe University, Bundoora, \\ Victoria, Australia; ${ }^{5}$ Brain Sciences \\ Institute, Swinburne University, \\ Melbourne, Australia
}

\author{
This article was published in the following Dove Press journal: \\ Clinical Interventions in Aging \\ 21 January 2013 \\ Number of times this article has been viewed
}

Background: Depression is common in elderly stroke survivors and has been associated with systemic inflammation. We aimed to investigate an elderly population of Swedish stroke patients for evidence of sustained peripheral inflammation 18 months post-stroke and to identify if inflammation is associated with post-stroke depression at 18 months post-stroke.

Methods: The Barthel Index was used to measure the level of impairment in activities of daily living at 3 days post-stroke. Serum concentrations of inflammation markers, ie, C-reactive protein and white cell count, were measured in 149 stroke patients (mean age $81 \pm 5.33$ years, $35 \%$ male) at 18 months post-stroke, and a comparison was made with an age-matched sample of elderly Swedish individuals who had not suffered a stroke. At the same visit, clinical depression was diagnosed according to the Diagnostic and Statistical Manual of Mental Disorders, Third Edition-Revised criteria. Severity of depression was assessed using the Montgomery-Asberg Depression Rating Scale (MADRS).

Results: Mean C-reactive protein and white cell count levels in stroke patients were significantly elevated at 18 months post-stroke compared with population probands. Disability scores were associated with MADRS depression scores, but C-reactive protein and white cell count were not.

Conclusion: We found evidence for a sustained peripheral inflammatory response at 18 months post-stroke. C-reactive protein and white cell count were not associated with depression in this study.

Keywords: geriatric, inflammatory, ischemia, mood

\section{Introduction}

Ischemic and hemorrhagic stroke affects 16 million people worldwide annually, with the risk of stroke doubling with each decade of life after the age of 55 years. ${ }^{1}$ Poststroke depression is particularly common, affecting at least one third of all stroke patients, and adversely affecting the response to rehabilitation and quality of life. ${ }^{2}$ A number of risk factors are associated with the presentation of post-stroke depressive symptomatology including stroke severity, ${ }^{3}$ severity of stroke disability, ${ }^{4}$ a history of prior stroke, ${ }^{4}$ a history of clinical depression, ${ }^{5}$ female gender, ${ }^{4,6,7}$ single relationship status, ${ }^{7}$ and cardiovascular disease. ${ }^{6}$ Recent research on post-stroke depression has begun to focus on the association between depression and inflammation-mediated apoptosis. $^{8}$

Ischemic stroke induces a central and peripheral inflammatory response. ${ }^{9}$ The brain responds to ischemic injury with an acute and prolonged inflammatory response, characterized by rapid infiltration of microglia, upregulation of proinflammatory cytokines,
Correspondence: Kate Noonan School of Psychological Science, La Trobe University, Melbourne, Australia

Tel +6I 394792290

Fax +6I 394791956

Email k.noonan@latrobe.edu.au 
and infiltration into the ischemic tissue. ${ }^{10}$ Recruitment of neutrophils has been detected within the first 24 hours of adult stroke. ${ }^{11}$ Macrophage recruitment starts later, with elevations seen at 3 days after stroke onset. ${ }^{12}$ Peripheral inflammatory molecules, ie, interleukin (IL)-1 $\beta$, IL-6, IL-18, and tumor necrosis factor alpha, are elevated within the first 24 hours, reach peak levels around 2-3 days, and remain elevated at 3 months post-stroke. ${ }^{13-15}$ Peripheral C-reactive protein and white cell count are increased within 24 hours of stroke onset, correlate with infarct size, and remain elevated at even 3 and 12 months after stroke onset. ${ }^{16}$ The current study aimed to identify whether there was evidence for sustained peripheral inflammation 18 months post-stroke, as defined by elevated C-reactive protein and white blood cell expression in peripheral blood samples, compared with an age-matched nonstroke cohort.

Upregulation of inflammatory cytokines has also been associated with clinical depression. ${ }^{2}$ Relatively few studies have examined the association between inflammation and post-stroke depression. A recent study found a significant association between serum IL-18 measured at day 7 poststroke and Montgomery-Asberg Depression Rating Scale (MADRS) depression scores at 2 weeks and 6 months after stroke onset. ${ }^{17}$ Studies have also found nonsignificant trends for elevated C-reactive protein in patients with post-stroke depression measured within a month of stroke. ${ }^{18-20}$ However, to our knowledge, no studies have examined the association between the inflammatory markers, C-reactive protein and white cell count, and depression in elderly stroke survivors as long as 1.5 years after stroke. Thus, it is important to clarify if these factors correlate with the post-stroke depression that has already been shown to affect at least a third of a much studied cohort of elderly stroke patients. ${ }^{21,22}$ Given the risk factors described above, this study aimed to identify whether there was evidence for sustained peripheral inflammation 18 months post-stroke, as defined by elevated C-reactive protein and white cell count expression, in peripheral blood samples compared with an age-matched cohort and to identify if the inflammatory markers, C-reactive protein and white cell count, female gender, cardiovascular comorbidity, and impairment in activities of daily living post-stroke, are associated with post-stroke depression among chronic stroke survivors.

\section{Materials and methods Subjects and study protocol}

Participants were selected from the Gothenburg 70+ Stroke study, ${ }^{23}$ that included individuals aged at least 70 years who presented to Sahlgrenska University Hospital, Gothenburg, Sweden, between February 1, 1993 and May 17, 1994 with an acute focal neurological deficit of no other apparent cause than cerebrovascular events and confirmed by routine investigations and acute computed tomography scans. Patients were excluded if brain computed tomography showed extracerebral or subarachnoid hemorrhage or a cerebral tumor, or if the patient was comatose $(n=17,20 \%)$. Patients were also excluded if they presented with symptoms beginning more than 7 days prior to admission, required specialized neurological care $(n=46,53 \%)$, lived in a nursing home at the time of admission, or if there was no available bed in the stroke unit. Patients were later contacted by letter, and subsequently by phone, to arrange a hospital-based appointment 1.5 years after stroke. If unable to attend the hospital, the examination took place in the participants' homes $(n=15,10 \%)$. Relevant medical information obtained from participants included risk factors for stroke, including history of previous stroke and cardiovascular disease (predating the index stroke). Informed consent was provided following written and verbal information to participants or their closest relatives. Ethics approval was granted by the ethics committee for medical research at the University of Gothenburg (33/94). Mean age at follow-up was $81 \pm 5.33$ (range 70.8-92.8) years.

\section{Control reference data}

Control participant reference data relating to C-reactive protein and white cell count were sourced from the National Health and Nutrition Examination Survey, 1999-2002, ( $n=4472$ men and 5212 women) and from the Cardiovascular Health Study ( $n=2227$ men and 2924 women), which are large population-based studies of community-dwelling elderly individuals aged 80 years and over. ${ }^{24,25}$

\section{Biomarker collection}

$\mathrm{C}$-reactive protein was analyzed from venous blood samples taken at 1.5 years after stroke drawn into gel tubes, turned over at least five times, and centrifuged according to the manufacturer's specifications for 10 minutes after coagulation. Serum was separated and stored at room temperature until analysis with turbidimetry. White cell count was analyzed by automated particle count of white blood cells taken in ethylenediamine tetra-acetic acid tubes at 1.5 years after stroke.

\section{Diagnostic criteria}

Assessments of depression were conducted by a neurologist/psychiatrist (TL) unaware of lesion information at the time of or during the interview ( 1.5 years after 
stroke). Clinical depression was diagnosed according to DSM-III-R (Diagnostic and Statistical Manual Of Mental Disorders, Third Edition-Revised $)^{26}$ criteria. Depressive symptomatology was assessed using the MADRS. ${ }^{27}$ The diagnostic procedure involved a consensus conference with a second neurologist and psychiatrist prior to determination of final diagnoses. The Barthel Index was used as a functional measure of independence in activities after stroke. ${ }^{28}$

\section{Statistical methods}

The statistical analysis was conducted using the SPSS version 18 package (SPSS Inc, Chicago, IL). Preliminary analyses were performed to ensure assumptions of normality, linearity, and homoscedasticity were met. When assumptions were violated, square-root transformations were performed to maintain a normal distribution. Transformed variables included C-reactive protein values and MADRS depression scores. All statistical analyses were performed using the transformed values. Hierarchical multiple regression was used.

\section{Results}

\section{Characteristics of observational cohort study population}

Table 1 shows the characteristics of stroke survivors. Of the 243 patients at stroke admission, $32 \%(n=77)$ had passed away while $7 \%(n=17)$ declined to participate, leaving 149 volunteer patients at the 1.5 -year follow-up. Of those participating, $66 \%$ were female $(n=67)$ and $34 \%$ were male $(\mathrm{n}=35)$. Mean age at follow-up was $81 \pm 5.33(70.8-92.8)$ years. Female MADRS scores were one point higher than those observed among male participants. A higher percentage of men than women were diagnosed with major depression (17.1\% versus $10.4 \%$ ) and depressive disorder not otherwise specified (DDNOS, $8.6 \%$ versus $4.4 \%$ ). More females were diagnosed with dysthymia $(16.4 \%$ versus $2.9 \%)$. Stroke disability scores were more severe among women than in men. More male than female participants had recurrent stroke $(25.7 \%$ versus $10.4 \%)$ and cardiovascular disease $(25.7 \%$ versus $23.9 \%)$. C-reactive protein levels and white cell counts were comparable between male and female participants.

\section{Comparison of study population with literature-sourced control data}

Independent-samples $t$-tests show that stroke survivors had significantly higher C-reactive protein levels $(t[101]=3.58$,
Table I Patient characteristics

\begin{tabular}{|c|c|c|c|}
\hline & $\mathbf{n}$ & $\begin{array}{l}\text { Mean (SE) } \\
\text { or \% (n) }\end{array}$ & Median \\
\hline \multicolumn{4}{|l|}{ Female } \\
\hline Age, years & 67 & $82.1(0.62)$ & 83.07 \\
\hline MADRS & 67 & $11.24(1.06)$ & 9 \\
\hline Major depressive episode & 67 & $10.4 \%(n=7)$ & \\
\hline Dysthymia & 67 & $16.4 \%(n=11)$ & \\
\hline DDNOS & 67 & $4.4 \%(n=3)$ & \\
\hline Stroke disability - mild & 67 & $92.5 \%(n=62)$ & \\
\hline Stroke disability - moderate & 67 & $4.5 \%(n=2)$ & \\
\hline Stroke disability - severe & 67 & $3.0 \%(n=2)$ & \\
\hline Previous stroke & 67 & $10.4 \%(n=7)$ & \\
\hline Previous heart disease & 67 & $23.9 \%(n=16)$ & \\
\hline $\mathrm{CRP}(\mathrm{mg} / \mathrm{L})$ & 67 & $2.83(0.10)$ & 2.57 \\
\hline $\operatorname{WCC}\left(10^{9} / \mathrm{L}\right)$ & 67 & $6.72(0.23)$ & 6.60 \\
\hline \multicolumn{4}{|l|}{ Male } \\
\hline Age, years & 35 & $79.70(0.76)$ & 79.98 \\
\hline MADRS & 35 & $10.15(1.58)$ & 7 \\
\hline Major depressive episode & 35 & $17.1 \%(n=6)$ & \\
\hline Dysthymia & 35 & $2.9 \%(n=1)$ & \\
\hline DDNOS & 35 & $8.6 \%(n=3)$ & \\
\hline Stroke disability - mild & 35 & $85.7 \%(n=30)$ & \\
\hline Stroke disability - moderate & 35 & $14.3 \%(n=5)$ & \\
\hline Stroke disability - severe & 35 & $0 \%(n=0)$ & \\
\hline Previous stroke & 35 & $25.7 \%(n=9)$ & \\
\hline Previous heart disease & 35 & $25.7 \%(n=9)$ & \\
\hline $\mathrm{CRP}(\mathrm{mg} / \mathrm{L})$ & 35 & $2.71(0.14)$ & 2.45 \\
\hline $\operatorname{WCC}\left(10^{9} / \mathrm{L}\right)$ & 35 & $6.40(0.26)$ & 6.20 \\
\hline
\end{tabular}

Abbreviations: MADRS, Montgomery-Asberg Depression Rating Scale; DDNOS, depressive disorder not otherwise specified; CRP, C-reactive protein; WCC, white cell count.

$P=0.001)$ and white cell counts $(t[101]=2.21, P=0.029)$ than individuals not affected by stroke.

\section{Analysis of depression}

Stroke patients diagnosed with depression had higher mean values for C-reactive protein and white cell count than those without depression (10.44 versus 10.17 for C-reactive protein and 6.85 versus 6.47 for white cell count). However, there was no significant difference in levels of C-reactive protein or white cell count between stroke patients diagnosed with major depression, dysthymia, or DDNOS and those that were not $(t[101]=0.09, P=0.932$ and $t[101]=1.04$, $P=0.303$, respectively).

Table 2 shows the nonstandardized (B) and standardized $(\beta)$ regression coefficients, the standard error of the coefficients (SE B), and the change in $\mathrm{R}^{2}$ after entry of each additional block of independent variables to the regression. To control for gender and stroke disability, which are strongly associated with post-stroke depression, ${ }^{3,6}$ these variables were entered together into the first block. Cardiovascular 
Table 2 Results from hierarchical multiple regression analysis

\begin{tabular}{lllll}
\hline & B & SE B & $\boldsymbol{\beta}$ & $\mathbf{R}^{2}$ \\
\hline Step I & & & & 0.087 \\
$\quad$ Constant & 5.23 & 0.76 & & \\
$\quad$ Gender & -0.50 & 0.26 & -0.18 & \\
$\quad$ Stroke disability & -0.62 & 0.27 & $-0.22^{*}$ & \\
Step 2 & & & & 0.049 \\
$\quad$ Constant & 5.10 & 0.75 & & \\
$\quad$ Gender & -0.58 & 0.26 & $-0.21^{*}$ & \\
Stroke disability & -0.63 & 0.26 & $-0.23^{*}$ & \\
$\quad$ Previous heart disease & 0.61 & 0.29 & $0.20^{*}$ & \\
$\quad$ Previous stroke & 0.37 & 0.37 & 0.10 & \\
Step 3 & & & & 0.013 \\
$\quad$ Constant & 4.94 & 0.94 & & \\
$\quad$ Gender & -0.56 & 0.26 & $-0.20^{*}$ & \\
Stroke disability & -0.66 & 0.26 & $-0.24^{*}$ & \\
$\quad$ Previous heart disease & 0.63 & 0.29 & $0.20^{*}$ & \\
$\quad$ Previous stroke & 0.37 & 0.36 & 0.10 & \\
$\quad$ CRP (mg/L) & 0.19 & 0.16 & 0.12 & \\
$\quad$ WCC (I0\%/L) & -0.05 & 0.07 & -0.06 & \\
\hline
\end{tabular}

Notes: Nonstandardized $(B)$, and standardized $(\beta)$ regression coefficients, standard error of coefficients (SE B), and change in $R^{2}$ after each block of independent variables associated with depression at I.5 years post-stroke, $R^{2}=0.01$ for step I, and 0.00 for steps 2 and 3 . $* P<0.05$.

Abbreviations: CRP, C-reactive protein; WCC, white cell count.

disease and previous stroke have also been identified to correlate highly with post-stroke depression, and therefore were entered into block two. The third block consisted of C-reactive protein and white cell count. Gender and stroke disability explained $8.7 \%$ of the variance in depression scores, with stroke disability contributing significantly to MADRS depression scores $(t=-2.34 ; P=0.02)$. Addition of cardiovascular disease and previous stroke explained an additional $4.9 \%$ of the variance in MADRS depression scores (the model as a whole explained a total of $13.6 \%$ ), with a history of cardiovascular disease significantly predicting MADRS depression scores $(t=2.09 ; P=0.04)$. Addition of C-reactive protein and white cell count explained an additional $1.3 \%$ of the variance in depression scores (the total amount explained by the model was $14.9 \%$ ), but C-reactive protein and white cell count were not independently associated with MADRS depression scores.

\section{Discussion}

To our knowledge, this is the first observational cohort study to examine the relationship between peripheral inflammation and depression in elderly stroke survivors at 1.5 years after stroke. We provide evidence of a sustained peripheral inflammatory response characterized by elevated levels of C-reactive protein and total white cell count at 18 months after stroke. This is consistent with previous research indicating that $\mathrm{C}$-reactive protein and white cell count are elevated at 3 and 12 months after stroke. ${ }^{9,29}$ It is also consistent with a study involving immunohistopathological characterization of inflammatory molecule expression in 137 cases of post-mortem human cerebral infarct (where the age of lesions ranged from one day to 53 years after stroke onset), suggesting that chronic inflammation may persist for years after stroke onset. ${ }^{12}$ Our results also showed that cardiovascular comorbidity was associated with depression at 18 months post-stroke. Many risk factors for stroke, such as diabetes, hypertension, and atherosclerosis, are associated with elevated inflammatory profiles..$^{30}$ Thus, it is likely that stroke patients have a pre-existing hyperinflammatory state that is associated with ischemic risk and recurrent stroke. ${ }^{31}$

Our analyses showed that, while C-reactive protein and white cell count were elevated among stroke survivors, these factors were not associated with MADRS depression scores or depression diagnosis (using DSM-III-R criteria for major depression, dysthymia or DDNOS). While different from some studies conducted in the general population, these results are consistent with results from other studies in patients with cardiovascular disease. ${ }^{32}$ Results are also consistent with our recent meta-analysis showing no association of poststroke depression with a variety of inflammatory mediators measured within one month after stroke (C-reactive protein, IL-18, IL-6, or tumor necrosis factor alpha). ${ }^{33}$ In particular, Jimenez et al, ${ }^{34}$ McKechnie et $\mathrm{al},{ }^{20}$ and Rothenburg ${ }^{35}$ found nonsignificant trends for higher levels of C-reactive protein in patients (recruited from stroke units) with post-stroke depression, measured 10-35 days after stroke onset and defined using DSM-IV (Diagnostic and Statistical Manual Of Mental Disorders, Fourth Edition, Text Revision) diagnostic criteria or by a cutoff score on the Center for Epidemiologic Studies Depression scale. White cell count has not previously been studied in relation to depression in stroke survivors. A recent study of the proinflammatory cytokine, serum IL-18, showed that serum IL-18 measured at 7 days was significantly associated with MADRS depression scores at 2 weeks and 6 months after stroke onset $(n=100) .{ }^{17}$ However, studies with fewer participants $(n=30$ and $n=47)$ and using DSM-IV diagnostic criteria to classify depression report nonsignificant trends for an association of IL-18 levels and post-stroke depression in the first 10 days after stroke. ${ }^{35,36}$ Trends for associations of other proinflammatory cytokines (IL-6 and tumor necrosis factor alpha) with post-stroke depression have also been reported at 7-30 days post-stroke. ${ }^{17,19,34}$ As expected, impairment in activities of daily living at 3 days after stroke onset independently predicted MADRS depression scores. This is consistent with previous research indicating that the level of 
post-stroke impairment predicts depression at $3,{ }^{37}$ and 6 and $12^{3}$ months post-stroke.

One strength of our study, is the thorough diagnostic workup in stroke patients. However, an important methodological limitation is that these data were collected in the 1990s, so DSM-III-R criteria were used to diagnose depression. Few studies have compared the diagnostic classification systems in relation to major depression. In a study of 176 outpatients with unipolar depression, DSM-III-R criteria diagnosed more patients with melancholia $(22.7 \%)$ than DSM-IV criteria $(16.5 \%) .{ }^{38}$ In another study of 65 patients with unipolar depression, melancholic depression was diagnosed more frequently using DSM-IV $(56.9 \%)$ than DSM-III-R criteria $(50.8 \%) .{ }^{39}$ Thus, some misclassification was inevitable. Our findings would benefit from replication with more markers of inflammation and with repeated measures of inflammatory markers in the same cohort. Measurement of inflammatory markers was performed on one occasion in this study. The results would be considered more robust with repeated measures of inflammatory markers over a period of time. While efforts were made to control for potentially confounding variables, infarct volume and brain volume were not available for assessment to add to our model.

\section{Conclusion}

The current study aimed to identify whether there was evidence for sustained peripheral inflammation 18 months following stroke as defined by elevated C-reactive protein and white cell count expression in peripheral blood samples compared with an age-matched cohort and to identify if the inflammatory markers, C-reactive protein and white cell count, were associated with post-stroke depression among chronic stroke survivors. In this study, elderly stroke survivors had elevated inflammatory markers 18 months post-stroke compared with age-matched population controls. However, this increased inflammatory state was not associated with depressive disorders, and thus cannot explain the increased prevalence of depression after stroke or distinguish those at an increased risk of depression.

\section{Acknowledgment}

The authors thank Christian Blomstrand and Ingmar Skoog for valuable support in the underlying studies and Valter Sundh. This study was supported by the Amlövs Research Foundation and the Göteborg-Södra Bohuslän R\&D office.

\section{Disclosure}

The authors report no conflicts of interest in this work.

\section{References}

1. Lloyd-Jones D, Adams R, Carnethon M, et al. Heart disease and stroke statistics - 2009 update: a report from the American Heart Association Statistics Committee and Stroke Statistics Subcommittee. Circulation. 2009;119(3):480-486.

2. Pohjasvaara T, Vataja R, Leppavuori A, Kaste M, Erkinjuntti T. Cognitive functions and depression as predictors of poor outcome 15 months after stroke. Cerebrovasc Dis. 2002;14(3-4):228-233.

3. Berg A, Palomaki H, Lehtihalmes M, Lonnqvist J, Kaste M. Poststroke depression: an 18-month follow-up. Stroke. 2003;34(1):138-143.

4. Paolucci S, Gandolfo C, Provinciali L, Torta R, Sommacal S, Toso V. Quantification of the risk of post-stroke depression: the Italian multicenter observational study DESTRO. Acta Psychiatr Scand. 2005; 112(4):272-278.

5. Hackett ML, Anderson CS. Frequency, management, and predictors of abnormal mood after stroke: the Auckland Regional Community Stroke (ARCOS) study, 2002 to 2003. Stroke. 2006;37(8):2123-2128.

6. Leentjens AF, Aben I, Lodder J, Verhey FR. General and diseasespecific risk factors for depression after ischemic stroke: a two-step Cox regression analysis. Int Psychogeriatr. 2006;18(4):739-748.

7. Zhang T, Wang C, Liu L, et al. A prospective cohort study of the incidence and determinants of post-stroke depression among the mainland Chinese patients. Neurol Res. 2010;32(4):347-352.

8. Pascoe MC, Crewther SG, Carey LM, Crewther DP. Inflammation and depression: why poststroke depression may be the norm and not the exception. Int J Stroke. 2011;6(2):128-135.

9. Emsley HC, Smith CJ, Gavin CM, et al. An early and sustained peripheral inflammatory response in acute ischaemic stroke: relationships with infection and atherosclerosis. J Neuroimmunol. 2003;139(1-2): 93-101.

10. Jin R, Yang G, Li G. Inflammatory mechanisms in ischemic stroke: role of inflammatory cells. J Leukoc Biol. 2010;87(5):779-789.

11. Nilupul Perera M, Ma HK, Arakawa S, et al. Inflammation following stroke. J Clin Neurosci. 2006;13(1):1-8.

12. Mena H, Cadavid D, Rushing EJ. Human cerebral infarct: a proposed histopathologic classification based on 137 cases. Acta Neuropathol. 2004;108(6):524-530.

13. Perini F, Morra M, Alecci M, Galloni E, Marchi M, Toso V. Temporal profile of serum anti-inflammatory and pro-inflammatory interleukins in acute ischemic stroke patients. Neurol Sci. 2001;22(4):289-296.

14. Fassbender K, Rossol S, Kammer T, et al. Proinflammatory cytokines in serum of patients with acute cerebral ischemia: kinetics of secretion and relation to the extent of brain damage and outcome of disease. J Neurol Sci. 1994;122(2):135-139.

15. Ferrarese $C$, Mascarucci $P, Z$ Zoia $C$, et al. Increased cytokine release from peripheral blood cells after acute stroke. J Cereb Blood Flow Metab. 1999;19(9):1004-1009.

16. Black S, Kushner I, Samols D. C-reactive protein. J Biol Chem. 2004; 279(47):48487-48490.

17. Yang L, Zhang Z, Sun D, Xu Z, Zhang X, Li L. The serum interleukin-18 is a potential marker for development of post-stroke depression. Neurol Res. 2010;32(4):340-346.

18. Schmidt W, Roesler A, Kretzschmar K, Ladwig K, Junker R, Berger K. Functional and cognitive consequences of silent stroke discovered using brain magnetic resonance imaging in an elderly population. JAm Geriatr Soc. 2004;52(7):1045-1050.

19. Rothenburg LS. Exploring the Biological Correlates of Post-Stroke Depression. Master of Science Thesis. Toronto, Canada: Graduate Department of Pharmaceutical Sciences, University of Toronto; 2008.

20. McKechnie F, Lewis S, Mead G. A pilot observational study of the association between fatigue after stroke and C-reactive protein. J R Coll Physicians Edinb. 2010;40(1):9-12. 
21. Linden T, Blomstrand C, Skoog I. Depressive disorders after 20 months in elderly stroke patients: a case-control study. Stroke. 2007;38(6): 1860-1863.

22. Pascoe MC, Crewther SG, Carey LM, Noonan K, Crewther DP, Linden T. Homocysteine as a potential biochemical marker for depression in elderly stroke survivors. Food Nutr Res. 2012:56.

23. Fagerberg B, Claesson L, Gosman-Hedstrom G, Blomstrand C. Effect of acute stroke unit care integrated with care continuum versus conventional treatment: A randomized 1-year study of elderly patients: the Goteborg 70+ Stroke study. Stroke. 2000;31(11):2578-2584.

24. Woloshin S, Schwartz LM. Distribution of C-reactive protein values in the United States. N Engl J Med. 2005;352(15):1611-1613.

25. Bovill EG, Bild DE, Heiss G, et al. White blood cell counts in persons aged 65 years or more from the Cardiovascular Health Study. Correlations with baseline clinical and demographic characteristics. Am J Epidemiol. 1996;143(11):1107-1115.

26. American Psychiatric Association. Diagnostic and Statistical Manual of Mental Disorders (3rd Edition, Revised). Washington, DC: American Psychiatric Association; 1987.

27. Montgomery SA, Asberg M. A new depression scale designed to be sensitive to change. Br J Psychiatry. 1979;134:382-389.

28. Mahoney FI, Barthel DW. Functional evaluation: The Barthel Index. Md State Med J. 1965;14:61-65.

29. Beamer NB, Coull BM, Clark WM, Briley DP, Wynn M, Sexton G. Persistent inflammatory response in stroke survivors. Neurology. 1998; 50(6):1722-1728.

30. Emsley HC, Hopkins SJ. Acute ischaemic stroke and infection: recent and emerging concepts. Lancet Neurol. 2008;7(4):341-353.
31. de Maat MP, Kluft C. Determinants of C-reactive protein concentration in blood. Ital Heart J. 2001;2(3):189-195.

32. Whooley MA, Caska CM, Hendrickson BE, Rourke MA, Ho J, Ali S. Depression and inflammation in patients with coronary heart disease: findings from the Heart and Soul Study. Biol Psychiatry. 2007;62(4): 314-320.

33. Noonan K, Crewther SG, Carey LM. Meta-analyses indicate associations between neuroendocrine activation, deactivation in neurotrophic and neuroimaging markers in depression after stroke. J Stroke Cerebrovasc Dis. November 10, 2012. [Epub ahead of print.]

34. Jimenez I, Sobrino T, Rodriguez-Yanez M, et al. High serum levels of leptin are associated with post-stroke depression. Psychol Med. 2009;39(7):1201-1209.

35. Rothenburg LS, Herrmann N, Swardfager W, et al. The relationship between inflammatory markers and post-stroke cognitive impairment. J Geriatr Psychiatry Neurol. 2010;23(3):199-205.

36. Bossu P, Salani F, Cacciari C, et al. Disease outcome, alexithymia and depression are differently associated with serum IL-18 levels in acute stroke. Curr Neurovasc Res. 2009;6(3):163-170.

37. Kotila M, Numminen H, Waltimo O, Kaste M. Depression after stroke: results of the FINNSTROKE Study. Stroke. 1998;29(2):368-372.

38. Lafer B, Nierenberg AA, Rosenbaum JF, Fava M. Outpatients with DSM-III-R versus DSM-IV melancholic depression. Compr Psychiatry. 1996;37(1):37-39.

39. Turkcapar MH, Akdemir A, Orsel SD, et al. The validity of diagnosis of melancholic depression according to different diagnostic systems. $J$ Affect Disord. 1999;54(1-2):101-107.
Clinical Interventions in Aging

\section{Publish your work in this journal}

Clinical Interventions in Aging is an international, peer-reviewed journal focusing on evidence-based reports on the value or lack thereof of treatments intended to prevent or delay the onset of maladaptive correlates of aging in human beings. This journal is indexed on PubMed Central, MedLine, the American Chemical Society's 'Chemical Abstracts Ser-

\section{Dovepress}

vice' (CAS), Scopus and the Elsevier Bibliographic databases. The manuscript management system is completely online and includes a very quick and fair peer-review system, which is all easy to use. Visit http://www.dovepress.com/testimonials.php to read real quotes from published authors. 